\title{
Evaluation of GPM IMERG Products and Estimation of Warm-Season Precipitation in Crimea
}

\author{
A. E. Anisimov ${ }^{1,}{ }^{凶}$, V. V. Efimov ${ }^{1}$, M. V. Lvova ${ }^{2}$ \\ ${ }^{1}$ Marine Hydrophysical Institute of RAS, Sevastopol, Russian Federation \\ ${ }^{2}$ Voeikov Main Geophysical Observatory, Saint Petersburg, Russian Federation \\ 凶anatolii.anisimov@mhi-ras.ru
}

Purpose. The study was aimed at the evaluation of the Integrated MultisatellitE Retrievals from GPM (IMERG) remote sensing dataset using ground observations and estimation of the 2006-2018 warmseason precipitation in the Crimean Peninsula.

Methods and Results. Evaluation of the IMERG dataset was performed using the meteorological station observations treated as the ground truth. We provided the multiyear statistical characteristics of precipitation amounts, frequency and intensity for different climate zones of the Crimean Peninsula. We considered the spatial variability of summer precipitation, bias and correlation between $I M E R G$ and the ground observations.

Conclusions. IMERG has a weaker spatial variability compared to the ground observations. The warm-season IMERG bias is small in the central and mountainous parts of Crimea, whereas the precipitation estimates in the coastal zones are substantially overestimated. The IMERG wet bias is mostly caused by the excessive rainfall frequency. The temporal variability of IMERG is in good agreement with the observations with an average correlation coefficient of 0.73 . For most of the metrics considered, warm-season IMERG precipitation significantly outperforms the other datasets in the central and mountainous parts of Crimea and could be used for practical tasks with certain precautions. At the same time, due to the lack of calibration over the marine areas, the quality of IMERG precipitation estimates in the coastal zones is reduced.

Keywords: GPM, IMERG, TRMM, E-OBS, evaluation, atmospheric precipitation, Crimea

Acknowledgements: the study of precipitation variability based on station data was funded by RFBR and Sevastopol municipality, research project No. 20-45-920017 "Quantitative estimates of precipitation in Southwestern Crimea and Sevastopol based on numerical modeling and radar observations". The processing of remotely sensed data was done within the framework of the state research project No. 0827-2018-0001 "Fundamental studies of the interaction processes in the oceanatmosphere system conditioning the regional spatial-temporal variability of natural environment and climate".

For citation: Anisimov, A.E., Efimov, V.V. and Lvova, M.V., 2021. Evaluation of GPM IMERG Products and Estimation of Warm-Season Precipitation in Crimea. Physical Oceanography, [ejournal] 28(4), pp. 454-467. doi:10.22449/1573-160X-2021-4-454-467

DOI: $10.22449 / 1573-160 \mathrm{X}-2021-4-454-467$

(C) A. E. Anisimov, V. V. Efimov, M. V. Lvova, 2021

(C) Physical Oceanography, 2021

\section{Introduction}

Evaluation of water balance components and freshwater resources is one of the main tasks of hydrology and geophysics. With the population growth and the economic development in certain regions of the world this issue has become extremely important. Climate change is an additional factor increasing the magnitude of the problem. It is known that in a number of regions the frequency and duration of drought periods is expected to rise, and freshwater access will be further limited; some notable examples of such regions include the Mediterranean and Southeastern Europe, as well as the Crimean Peninsula. [1]. So far, Crimea has already faced serious problems with water resources, mainly 454 
caused by prolonged dry periods. At the same time, Crimea lacks the adequate infrastructure for monitoring, analyzing and forecasting the hydrological processes. The existing rain gauge and meteorological stations networks are functioning, but not developing; and the coverage of the peninsula by the rain gauges $(0.09$ per $100 \mathrm{~km}^{2}$ ) remains insufficient even according to the minimum World Meteorological Organization requirements for flat areas $\left(0.17\right.$ per $\left.100 \mathrm{~km}^{2}\right)$, and complex terrains require much better coverage. As a result, vast areas of Crimea are not covered by observation posts: for example, there are no gauges on the Karabi-Yaila plateau, which is a catchment area for important rivers feeding the water bodies of Eastern Crimea.

The development of remote sensing methods has significantly expanded the hydrological analysis and forecasting capabilities. This applies to both soil moisture [2] and precipitation [3] products, which are the key components of water balance. One recent such product, based on data combination of instruments from several Earth satellites, is the Integrated MultisatellitE Retrievals from GPM (IMERG) dataset, developed jointly by $N A S A$ and JAXA as part of the Global Precipitation Measurement Mission (GPM) [4]. Despite the fact that IMERG is a new product, it is actively used all over the world for several applications. A number of papers has been published on IMERG verification, e. g. for Europe [5], including separate studies for Spain [6] and the Netherlands [7], China [8] and many other regions [9 and references therein]. Attempts have also been made to validate $I M E R G$ precipitation over the ocean where stationary observations are not available [10].

The present paper is devoted to the IMERG dataset verification for the territory of Crimean Peninsula for 2006-2018. To the authors' knowledge, this is the first time such an analysis of satellite precipitation is carried out for Russia. The primary objective of this work is to obtain quantitative estimates of IMERG precipitation at various spatial and temporal scales and to assess its applicability as a tool for hydrological modeling and validation of atmospheric models. IMERG verification is carried out by comparing the characteristics of remotely-sensed precipitation with ground-based observations and gridded precipitation datasets. Most of the ground precipitation measurements were not used during the IMERG preparation and therefore present as an independent observation.

One of the GPM program goals is to refine estimates of solid precipitation during the cold season. However, it should be noted that remote sensing methods of precipitation in the cold season have a number of fundamental limitations. When compared with the gauge data, they are often characterized by larger discrepancies compared to the summer period [11]. For the radar method, this is associated both with the peculiarity of radio wave propagation in snowfalls (the dielectric constant of snowflakes increases several times during the melting process and cannot be adequately averaged within the pulse volume), and with errors of precipitation measurements. Wind-shielded rain gauges capture $\sim 70 \%$ of actual precipitation in the form of snow, and only about 50\% without wind shield [12]. A preliminary analysis of the IMERG performance compared to ground-based pluviographs in the cold season also demonstrated a significant IMERG wet bias. Therefore, we have decided to limit this study to the warm season from April to September inclusive. 


\section{Data}

In the current study, we used IMERG version $6 B$-Final satellite precipitation dataset based on the self-titled algorithm of the GPM program, which is currently the most advanced remote sensing precipitation product [4]. With a spatial resolution of $0.1 \times 0.1^{\circ}$ and a temporal resolution of $30 \mathrm{~min}$ (the present study uses daily precipitation accumulations), IMERG uses a number of various satellite data sources. The algorithm main element is the data from two instruments (dualfrequency radar and passive multi-channel microwave radiometer) on board GPM Core Observatory - the program's primary satellite, launched into the orbit in 2013. In addition, the IMERG algorithm accumulates data obtained from other available passive microwave radiometers, being processed and calibrated (e.g. NOAA AMSU, MetOp, DMSP - currently 10 instruments) [13]. In areas not covered by low-orbiting microwave radiometers, precipitation is calculated using $G P M$-calibrated data from geostationary satellites' infrared radiometers (Meteosat, GOES, Himawari, etc.). The most important IMERG component is the morphing algorithm in which displacement vectors are calculated for each precipitating system and, for those time steps when data from high-quality microwave radiometers are not available, precipitation is calculated for the displaced systems. In the V06 version, the morphing algorithm was updated and the MERRA-2 reanalysis [14] is now used to calculate the vectors. Initially, the IMERG product has been available since 2014, but later an algorithm has been applied to the period prior to the GPM Core Observatory launch, extending the dataset until 1998, when the Tropical Rainfall Measuring Mission (TRMM) satellite was the main precipitation monitoring instrument. Just like $G P M$, TRMM carried a dedicated radar for measuring precipitation (the first at that time) and a two-channel microwave radiometer. Thus, IMERG is a continuous precipitation dataset from 1998 to the present with a unified data processing algorithm.

Two precipitation products are available within IMERG, one with and the other without ground-based gauge calibration. In the present work, we only use the calibrated version. To calibrate IMERG, the monthly precipitation totals from the Global Precipitation Climatology Center (GPCC) ground-based observational dataset is used [15]. IMERG calibration strongly depends on the number of gauges in the GPCC cell. Low gauge coverage will reduce the GPCC calibration weight.

The $E-O B S$ dataset (version $20 \mathrm{e}$ is used in this work) is a gridded observational dataset based on kriging on a regular grid of $0.25 \times 0.25^{\circ}[16]$. This spatial resolution is the best among similar products for the territory of Crimea. E-OBS is the most complete and detailed gridded product for Europe and one of its main purposes is the verification of atmospheric models on climatic scales $[17,18]$. In addition, $E-O B S$ is sometimes used for hydrological modeling [19-21]. Alongside the E-OBS dataset, we also use the aforementioned GPCC gridded dataset with a spatial resolution of $1 \times 1^{\mathrm{o}}$, which is used in IMERG for monthly calibration (the full version is used for 2006-2016, whereas the monitoring version is used for 2017-2018). Previously, none of these datasets were applied for detailed analysis of precipitation variability in Crimea. The quality of these products largely depends on the number of meteorological stations distributed for international exchange which could therefore be used for 
kriging. The datasets themselves might require a separate verification procedure (this issue will be followed up below).

The daily precipitation records from 21 meteorological stations in Crimea for 2006-2018 have been used as a basic tool for verification. In total, there are 24 meteorological stations in Crimea. Data from three stations were unavailable and were not included in this study (Simferopol (city), Sevastopol and Opasnoye), but for each of those there is a nearby station at a distance of several kilometers, and data from these stations have been used in the analysis (Simferopol (airport), Chersonesos lighthouse and Kerch).

For comparison with observations at weather stations, the IMERG and E-OBS data were interpolated with the inverse distance weighting method using the values in the two nearest grid cells. The IMERG cells where water surface coverage was above $35 \%$ were excluded from the analysis.

\section{Results}

Spatial variability. For ease of comparison with previously published results, we show the rainfall spatial distributions for the 3-month summer period (Fig. 1), not for the entire 6-month period considered in this paper. According to the precipitation distribution map (Fig. 1, c), their maximum amount is expected to be recorded at mountain stations - Angarskii Pass $(220 \mathrm{~mm})$ and Ai-Petri $(240 \mathrm{~mm})$. A characteristic feature of the spatial distribution of precipitation according to ground-based observations is the contrast between the amount of precipitation at coastal stations (especially in the west of Crimea, $\sim 90 \mathrm{~mm}$ ) and in the central part of the peninsula $(\sim 130 \mathrm{~mm})$. In general, the distribution of precipitation according to the data of meteorological stations is in good agreement with the previously known climatological estimates of precipitation over Crimea $[22,23]$. The spatial resolution of the coarse GPCC dataset (Fig. 1, d) does not permit carrying out a detailed analysis of the precipitation distribution, but allows tracing the contrast between the western and central part of the peninsula and the Crimean Southern Coast. Physical mechanisms of excessive precipitation in the central regions of Crimea in comparison with the coastal areas might be linked to the sea breeze circulation. The daytime sea breeze pushes convective systems inland; as a result, daytime precipitation tends to develop more often at a distance of 50-100 km from the coast. For example, the amount of summer precipitation in Simferopol is $120 \mathrm{~mm}$, while in Sevastopol it is only $70 \mathrm{~mm}$. The breeze circulation mechanism in Crimea has been discussed in detail in [24, 25]. Despite the sufficiently high resolution, the $E-O B S$ dataset does not resolve the spatial structure of precipitation in sufficient detail (Fig. 1, b). In general, E-OBS systematically underestimates precipitation (especially in the central part of Crimea), with the exception of the maximum values in the mountainous regions of the peninsula. Other details, in particular the contrast between the precipitation amount in the central part of the peninsula and in the coastal zones are not reflected. The small precipitation maximum in the Kerch Peninsula is probably present because the Kerch meteorological station is one of the two included in the $E-O B S$ analysis pool. 

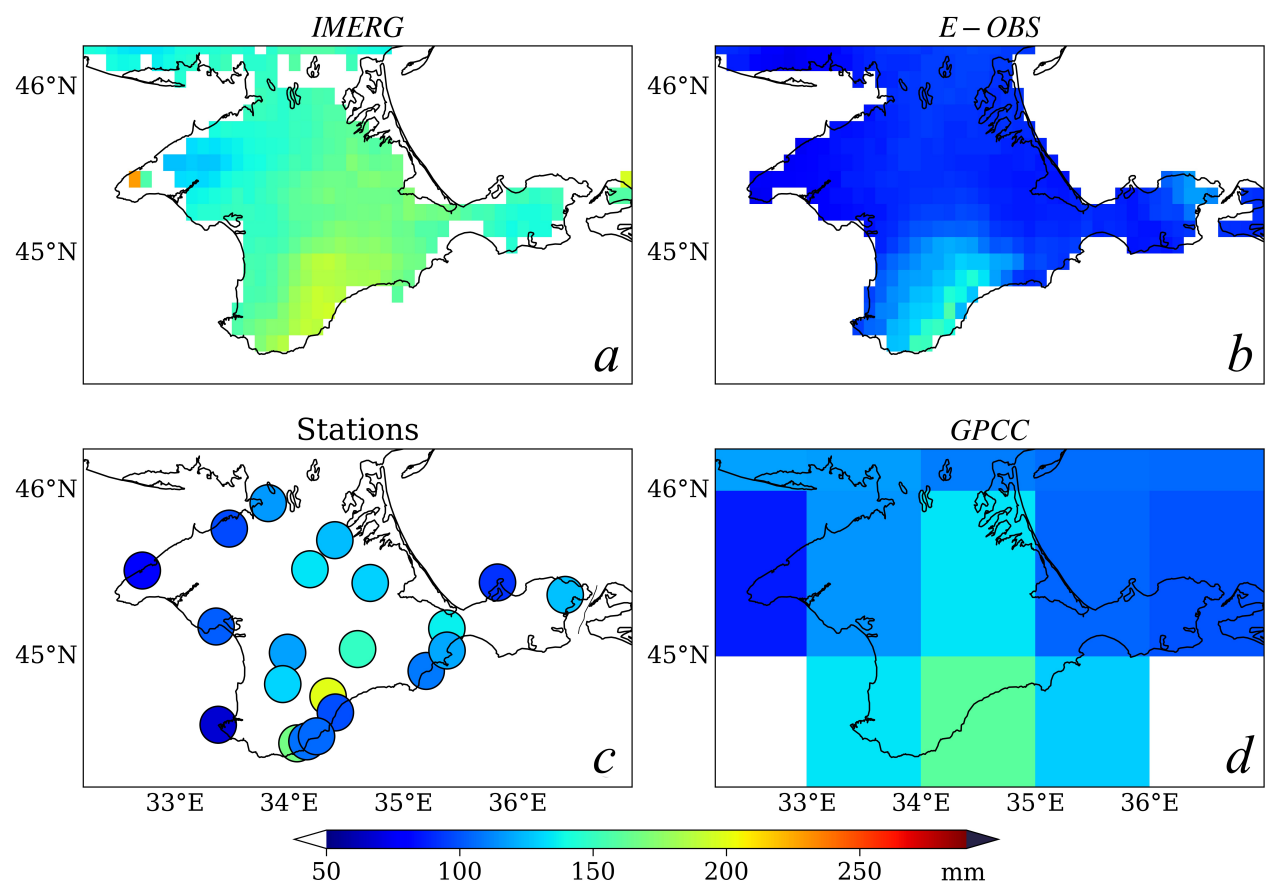

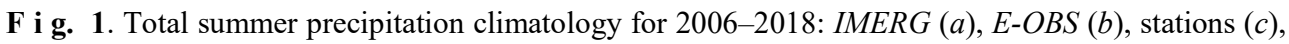
and $G P C C(d)$

According to the IMERG satellite dataset (Fig. 1, a), the maximum amount of precipitation is also observed in mountainous regions. It is worth noting the presence of sharp gradients in IMERG, consistent with the boundaries of the GPCC cells, which reflects the ground-based calibration procedure carried out for the IMERG. A gradient between the western and central parts of Crimea is present in IMERG, but it is significantly weakened due to the overestimation of rainfall over the western coast of Crimea. This overestimation is small in the central part of the peninsula ( $\sim 150 \mathrm{~mm}$ compared to $130 \mathrm{~mm}$ ), and in the mountainous locations the IMERG rainfall is even slightly lower than observed ( $180 \mathrm{~mm}$ compared to $200-220 \mathrm{~mm}$ ). However, the wet bias takes its peak at the coastal stations with the amount of precipitation overestimated by $\sim 50 \%$.

A substantial IMERG wet bias in the coastal zones can be regarded as expected. Due to the absence of stationary observations, the IMERG calibration is not carried out above the water surface and as a result, the quality of IMERG products is significantly worse than that over land. In [26], the IMERG precipitation was validated against the sea buoy data in the Indian Ocean and showed a significant overestimation of the precipitation amount (by 35-40\%) and frequency. Due to the morphing technique, this systematic error also affects the coastal land areas, where small-scale terrain features are already present and barely resolved by satellite instruments, leading to additional errors. Without giving illustrations, it is noted that this wet bias is even more pronounced in the cold season. This could be explained by the fundamental shortcomings of the radar method in estimating solid states (for this reason, this work considers only 
the warm season). It is also important to note that the precipitation variability in the catchment areas, which, in contrast to the coastal parts, have a primary impact on the filling of rivers and reservoirs, is of fundamental importance for hydrological modeling. For the Crimean Peninsula, these are mountainous and foothill areas [27]. In view of the above, we will mainly focus on precipitation in the central and mountainous parts of Crimea.

Temporal variability. Long-term series of total monthly precipitation at 9 Crimean stations in central and mountainous regions according to IMERG, E-OBS and meteorological stations, as well as the number of meteorological stations used in $G P C C$ (and for IMERG calibration) are shown in Fig. 2. Monthly correlation coefficients between the gauge measurements and satellite estimates are also shown. It can be seen that the number of stations included in GPCC has decreased in recent years compared to previous periods - in 2018, only four Crimean stations (Simferopol, Ai-Petri, Chernomorskoye and Kerch) were included in GPCC. Fig. 3 shows the scatter plots of monthly rainfall from IMERG and weather stations. The IMERG data is generally in better agreement with the gauge measurements than $E-O B S$. Note that in some months with intense rainfall, the IMERG estimates are underestimated in comparison with the ground-based observations (this is especially pronounced for the Angarskii Pass and Ai-Petri mountain stations), but in most cases, the amount of precipitation in IMERG is overestimated. In turn, the $E-O B S$ estimates are significantly underestimated. This has already been noted in the spatial distributions - an expected result, as only two Crimean stations are included in the $E-O B S$ database. The average correlation coefficient in 9 meteorological stations away from the coast is 0.78 , compared to 0.69 for coastal stations. The correlation coefficient averaged over all 21 stations is 0.73 . The obtained correlations are generally comparable with those given in other works [5]. The results of IMERG comparisons with gauge measurements are considerably better than those for $E-O B S$. IMERG correlations are significantly larger, with an average correlation coefficient between $E-O B S$ and inland gauge measurements of 0.45 ( 0.42 for coastal stations and an average value of 0.43$)$.

To evaluate IMERG prior to and after the launch of the GPM Core Observatory (as well as after the increase in the number of other instruments passive radiometers used in IMERG), we have considered the correlation coefficients for 2006-2013 and 2014-2018. The consistency of IMERG with the observational data directly depends on the number of gauges used in GPCC [28], therefore, to be consistent, we have only selected those locations where the number of GPCC gauges stayed constant during the study period. This condition is met by 9 stations (Evpatoriya, Karadag, Kerch, Pochtovoye, Simferopol, Ishun', Razdol'noe, Chersonesos lighthouse (Sevastopol) and Chernomorskoye). The average correlation coefficient with gauge measurements for 2014-2018 (0.77) is higher than in 2006-2013 (0.70); and this result is statistically significant, according to the paired $t$-test. Unfortunately, in recent years, many Crimean stations have stopped transferring the data to international databases; as a result, the number of observations used for IMERG calibration has decreased (Fig. 2). 

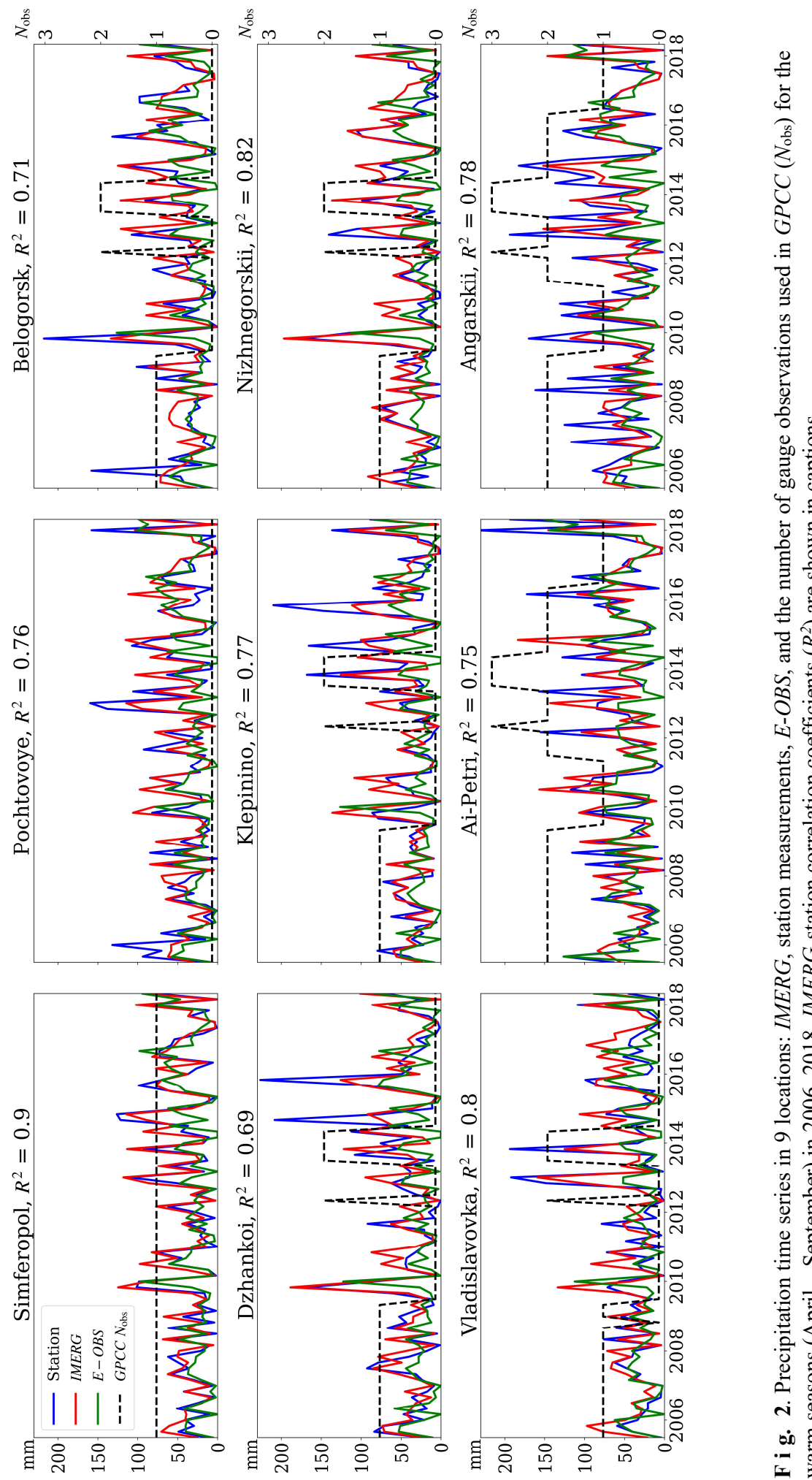

0

넌

$\ddot{0} \frac{\infty}{0}$

율

ヨ.

总

छ

总专

.

ठ

ㄱ ¿

म 

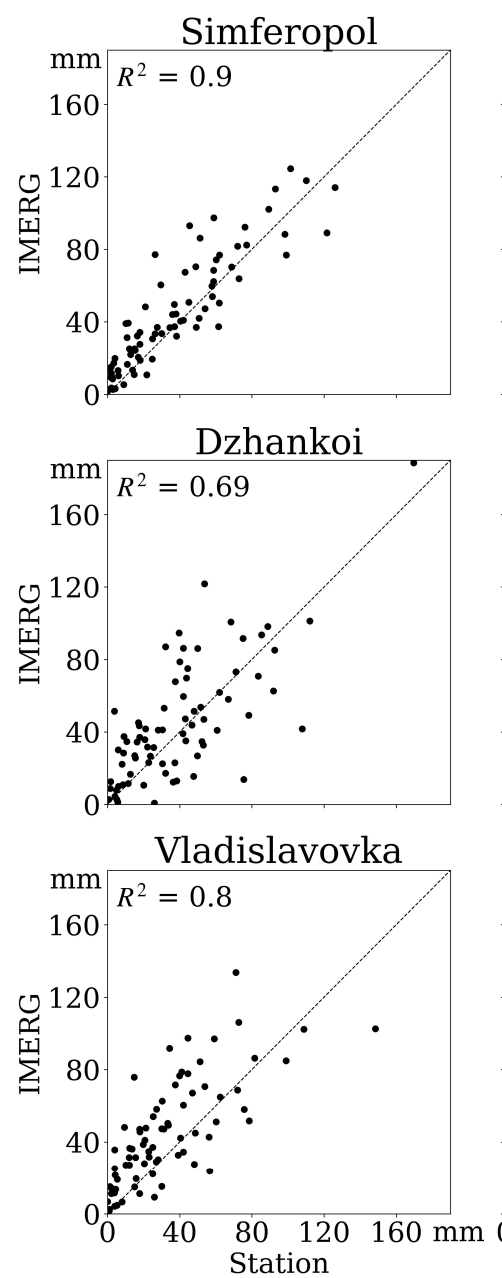
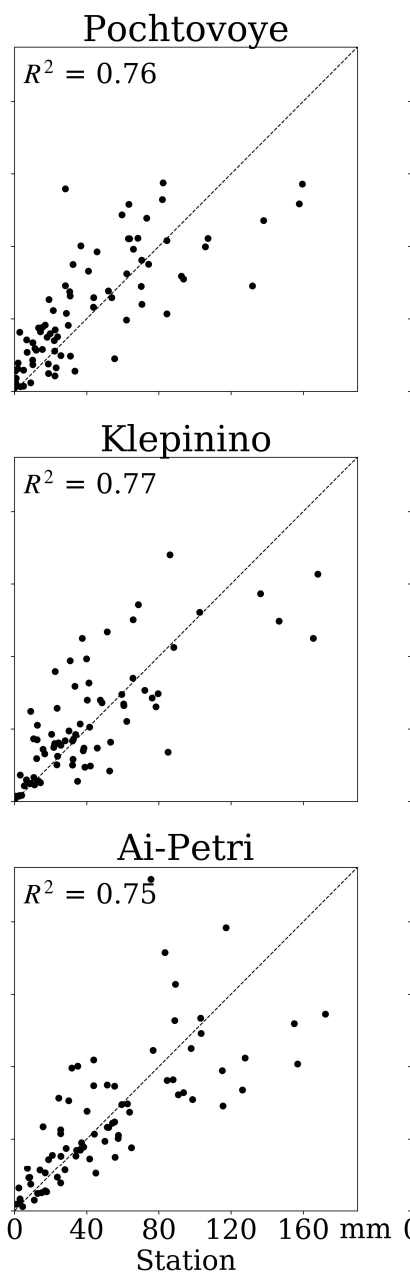
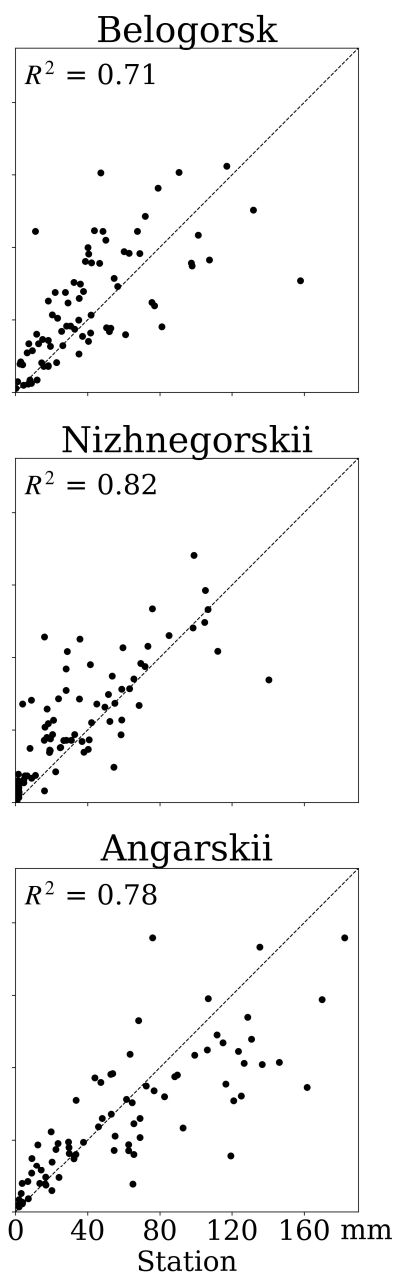

F i g. 3. Scatter plots of $I M E R G$ vs. station monthly precipitation accumulations

Fig. 4 shows the semiannual variation of the total monthly rainfall in 9 locations according to various sources. In most locations, despite the large values of interannual variability (the standard deviation reaches $70-80 \%$ of the mean values for both datasets), the long-term variation of IMERG precipitation is consistent with observations. According to $I M E R G$, the warm-season rainfall reaches its maximum on June, and the minimum values are expectedly seen in August. The absolute values of monthly precipitation totals in IMERG are somewhat overestimated in comparison with observations, with the exception of the mountainous stations of Ai-Petri and Angarskii Pass. This result is in contrast with the above-mentioned underestimation of peak rainfall. The $E-O B S$ rainfall semiannual variation is substantially different from the IMERG and gauge estimates. The maximum rainfall values in July are significantly underestimated compared to the station measurements. 

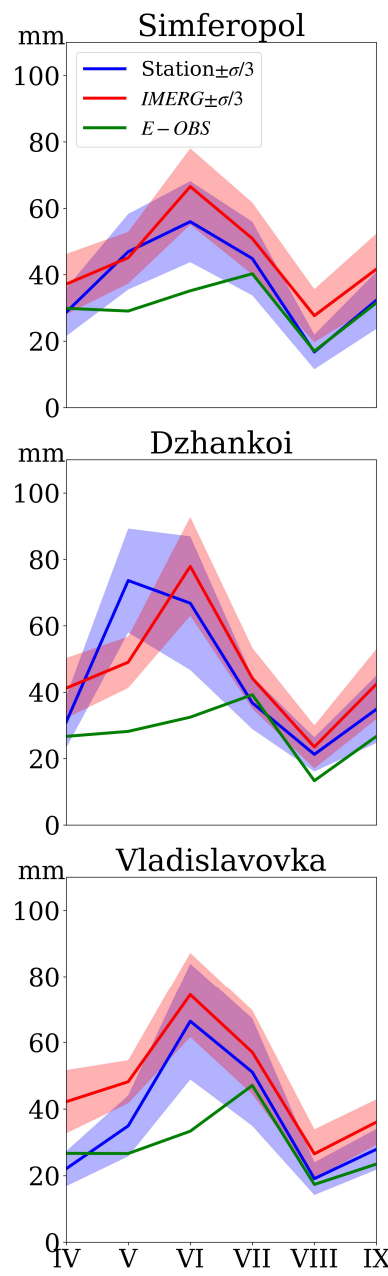

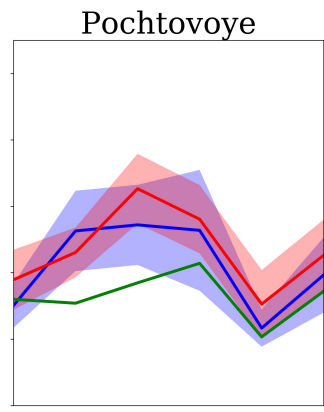

Klepinino

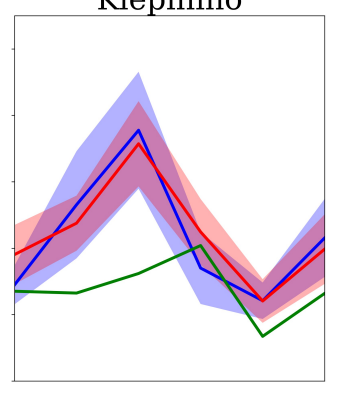

Ai-Petri

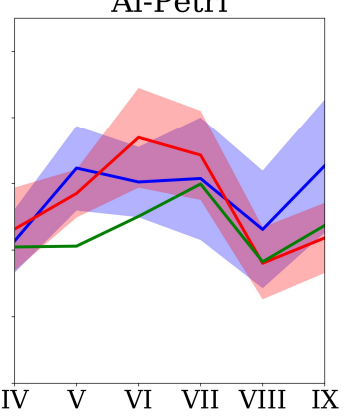

Belogorsk

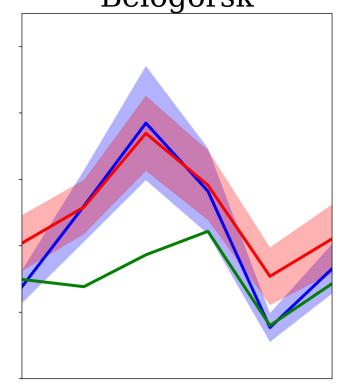

Nizhnegorskii

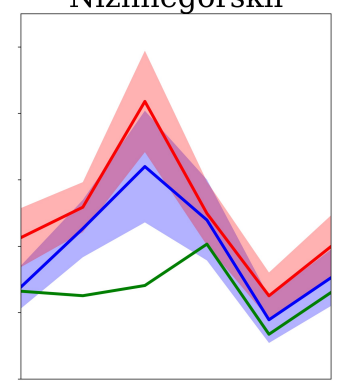

Angarskii

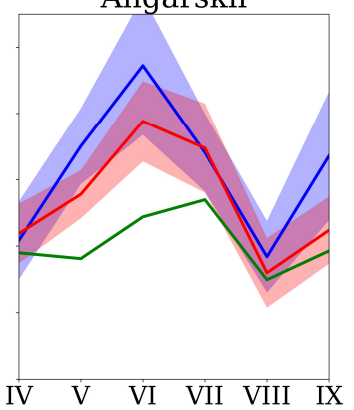

F i g. 4. Annual variation of monthly precipitation accumulations averaged for the warm seasons (April - September) in 2006-2018: IMERG, station measurements, and E-OBS. Shaded is the interval of one-third of standard deviation

Fig. 5 shows the semiannual variation of the average monthly frequency and intensity of daily precipitation (over $1 \mathrm{~mm}$ ). According to the gauge measurements, the rainfall frequency maximum varies from point to point, while according to the IMERG estimates, it always corresponds to June, as does the maximum amount of precipitation (Fig. 4). In general, the variation of the precipitation frequency and intensity according to IMERG is quite stable for the entire territory of Crimea and varies only slightly from point to point, demonstrating the already noted undersampling of the local small-scale precipitation features in IMERG.

We have noted that IMERG tends to underestimate the peak rainfall in some months, whereas there is a wet bias for rainfall totals. The details of the frequency and intensity variation explain this contradiction. It is evident that the mean intensity of precipitation in most locations according to observational data $(8.8 \mathrm{~mm})$ is higher than that of the IMERG $(7.1 \mathrm{~mm})$ and $E-O B S(6.3 \mathrm{~mm})$ datasets, especially at stations in the steppe zone (Dzhankoi, Nizhnegorskii, Klepinino and 
Vladislavovka). The IMERG rainfall frequency is, however, somewhat overestimated (0.21 compared to 0.15 and 0.16 according to station and E-OBS records, respectively). Thus, the IMERG rainfall tends to be more frequent, but less intense than observed.
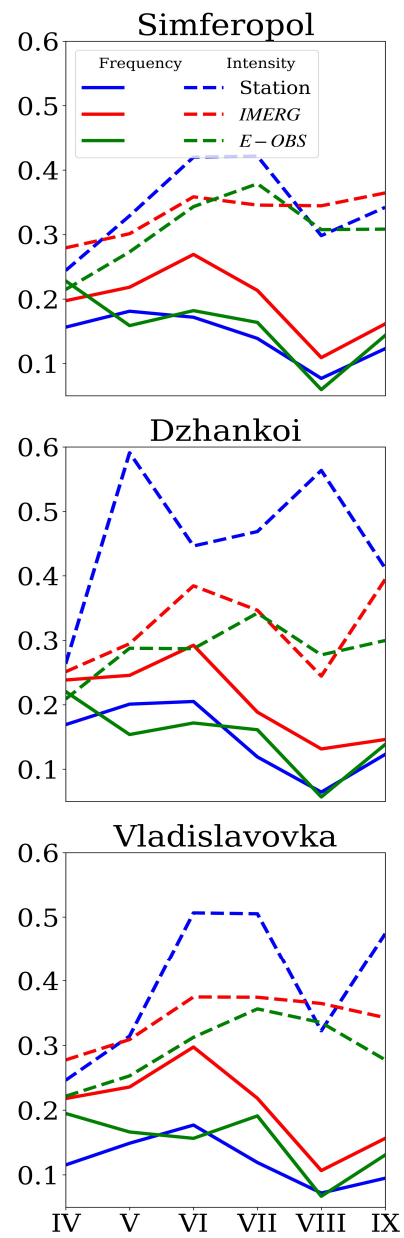

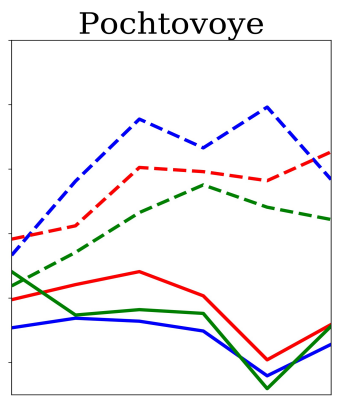

Klepinino

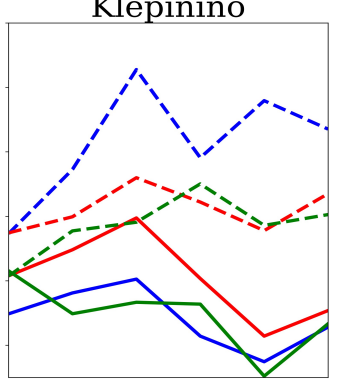

Ai-Petri

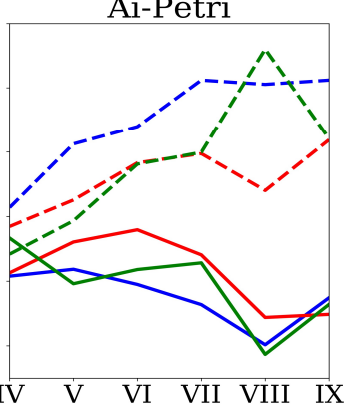

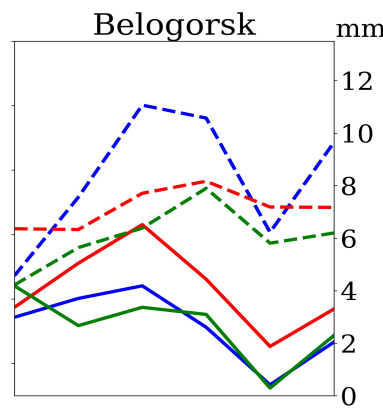

Nizhnegorskii $\mathrm{mm}$

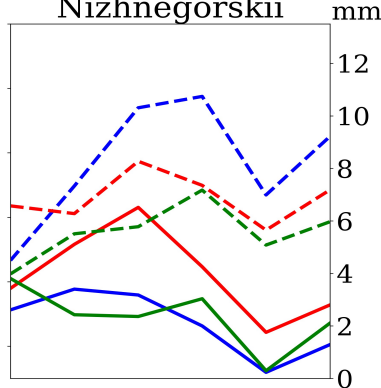

Angarskii

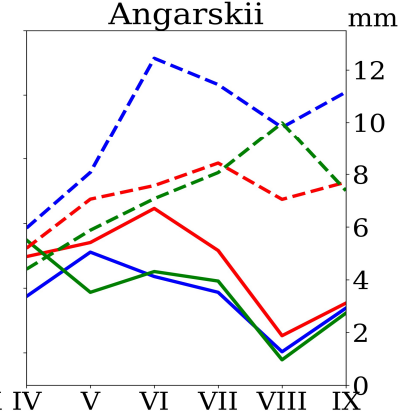

F i g. 5. The same as on Fig. 4, but for the monthly-averaged daily precipitation frequency and intensity calculated using $1 \mathrm{~mm} \cdot$ day $^{-1}$ threshold

This conclusion is also confirmed by histograms of daily precipitation sums (Fig. 6). Days with rainfall below $20 \mathrm{~mm} \cdot$ day $^{-1}$ are observed in IMERG more often, explaining the increased frequency. On the other hand, days with rainfall above $20-25 \mathrm{~mm} \cdot$ day $^{-1}$ occur less frequently in IMERG compared to what is observed, resulting in reduced mean intensity. The number of days with heavy precipitation according to the $E-O B S$ data (except for the Ai-Petri station) is much less than in the other two datasets. This result is consistent with [28], where a significant $I M E R G$ dependence on precipitation intensity in mainland China was shown: underestimation of heavy rainfall event and overestimation of weak ones. 


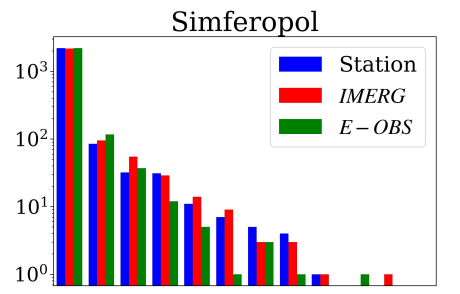

Dzhankoi
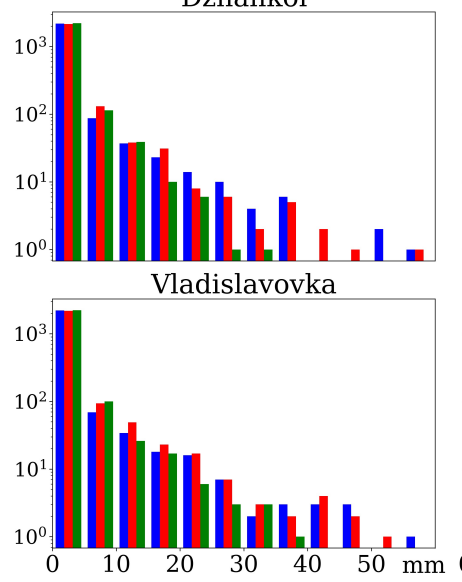

Pochtovoye

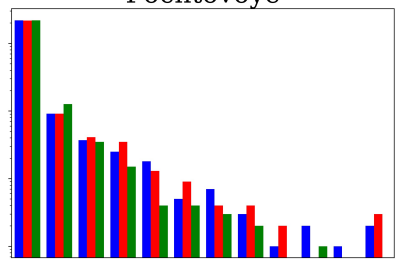

Klepinino

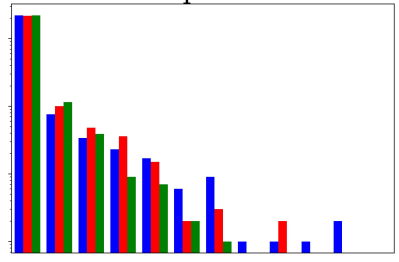

Ai-Petri

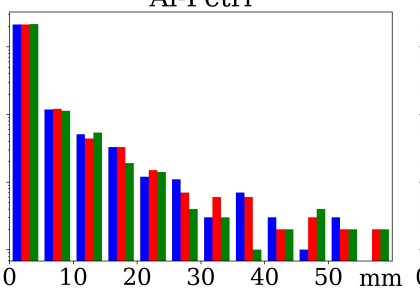

Belogorsk

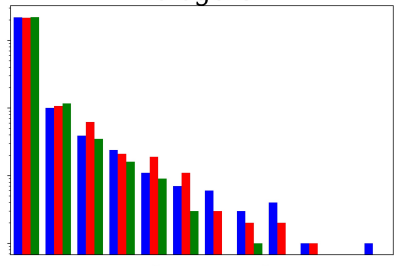

Nizhnegorskii

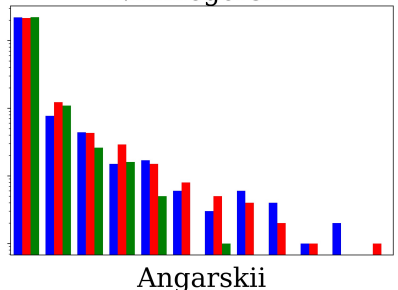

Angarskii

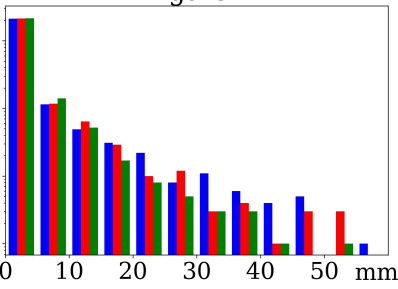

F i g. 6. Histograms of daily precipitation accumulations in 9 locations for the warm seasons (April September) of 2006-2018: IMERG, station measurements, and E-OBS

\section{Conclusion}

The issues raised in the present study have a direct practical application. A potential tool for water resources monitoring and forecasting could be presented by a numerical system that includes either a separate hydrological component or a numerical weather prediction model with a hydrological module. The key elements of such a system should be high-quality precipitation datasets. Satellite remotely-sensed precipitation could either act as an independent model input source, or as a tool for model verification. In any case, in the absence of a detailed ground observational network, remote sensing data are an extremely important source of information.

Based on the IMERG verification for the territory of Crimea, the following conclusions can be summed up.

1. A key spatial feature of summer precipitation in Crimea is the lower values in the western and eastern coastal zones compared to the inland steppe regions. This is the main source of discrepancies between station measurements and remote sensing data: in IMERG, the spatial gradients between the coastal and inland regions of Crimea are much less pronounced. While in inland Crimea the summer precipitation bias is small $(+15 \%$ in the central part of the peninsula, $-10 \%$ in mountainous regions), in the western coast of Crimea, satellite precipitation estimates are significantly (up to $50 \%$ ) overestimated, smoothing the coast-inland gradient. Nevertheless, the $I M E R G$ and $E-O B S$ biases are generally comparable.

2. The averaged temporal coefficient of correlation with gauge measurements on 21 stations for IMERG (0.73) is significantly higher than for E-OBS (0.43). 
The correlations calculated after the introduction of GPM Core Observatory satellite (since 2014) are significantly higher than the previous period. The correlation coefficients at the coastal stations (0.69) are lower compared to the central and mountainous regions (0.79). Both the spatial and temporal discrepancies are partly caused by systemic shortcomings of the IMERG algorithm in coastal zones, which have been already noted in other works.

3. The maximum in IMERG semiannual variation at inland locations is reasonably captured and better corresponds to observations as compared to $E-O B S$. However, it is necessary to note the overestimation of daily precipitation frequency by $30-40 \%$ and the underestimation of intensity by $20 \%$. Thus, weaker but more frequent precipitation is found in IMERG. This is reflected both in the monthly precipitation totals, and in the daily peak values that are smoothed. Daily precipitation frequency bias leads to overestimation of the monthly totals and conditions the overall wet bias.

Based on the above, we can conclude that the quality of the IMERG satellite dataset significantly outperforms other alternative sources $(E-O B S)$ and, thus, $I M E R G$ has a better prospect for practical application. It should be noted that Crimea is rather small in area (in comparison with other territories for which the IMER $G$ was previously analyzed), being almost an island object with a complex topography, substantially limiting the applicability of remote sensing tools. Nevertheless, good temporal dynamics and reasonable overall quality of IMERG datasets for mountainous zones acting as catchment areas suggest the good IMERG potential to be applied as a model input forcing and for analyzing the precipitation variability processes in Crimea. To deal with spatial biases (in particular, the wet bias in the coastal zone), bias correction techniques could be applied.

\section{REFERENCES}

1. Spinoni, J., Barbosa, P., Bucchignani, E., Cassano, J., Cavazos, T., Christensen, J.H., Christensen, O.B., Coppola, E. and Evans, J. [et al.], 2020. Future Global Meteorological Drought Hot Spots: A Study Based on CORDEX Data. Journal of Climate, 33(9), pp. 36353661. https://doi.org/10.1175/JCLI-D-19-0084.1

2. Entekhabi, D., Njoku, E.G., O’Neill, P.E., Kellogg, K.H., Crow, W.T., Edelstein, W.N., Entin, J.K., Goodman, S.D. and Jackson, T.J. [et al.], 2010. The Soil Moisture Active Passive (SMAP) Mission. Proceedings of the IEEE, 98(5), pp. 704-716. https://doi.org/10.1109/JPROC.2010.2043918

3. Maggioni, V. and Massari, C., 2018. On the Performance of Satellite Precipitation Products in Riverine Flood Modeling: A Review. Journal of Hydrology, 558, pp. 214-224. https://doi.org/10.1016/j.jhydrol.2018.01.039

4. Hou, A.Y., Kakar, R.K., Neeck, S., Azarbarzin, A.A., Kummerow, C.D., Kojima, M., Oki, R., Nakamura, K. and Iguchi, T., 2014. The Global Precipitation Measurement Mission. Bulletin of the American Meteorological Society, 95(5), pp. 701-722. https://doi.org/10.1175/BAMSD-13-00164.1

5. Navarro, A., García-Ortega, E., Merino, A., Sánchez, J.L., Kummerow, C. and Tapiador, F.J., 2019. Assessment of IMERG Precipitation Estimates over Europe. Remote Sensing, 11(21), 2470. https://doi.org/10.3390/rs11212470

6. Tapiador, F.J., Navarro, A., García-Ortega, E., Merino, A., Sánchez, J.L., Marcos, C. and Kummerow, C., 2020. The Contribution of Rain Gauges in the Calibration of the IMERG Product: Results from the First Validation over Spain. Journal of Hydrometeorology, 21(2), pp. 161-182. https://doi.org/10.1175/JHM-D-19-0116.1 
7. Rios Gaona, M.F., Overeem, A., Leijnse, H. and Uijlenhoet, R., 2016. First-Year Evaluation of GPM Rainfall over the Netherlands: IMERG Day 1 Final Run (V03D). Journal of Hydrometeorology, 17(11), pp. 2799-2814. https://doi.org/10.1175/JHM-D-16-0087.1

8. Guo, H., Chen, S., Bao, A., Behrangi, A., Hong, Y., Ndayisaba, F., Hu, J. and Stepanian, P.M., 2016. Early Assessment of Integrated Multi-Satellite Retrievals for Global Precipitation Measurement over China. Atmospheric Research, 176-177, pp. 121-133. https://doi.org/10.1016/j.atmosres.2016.02.020

9. Wang, H. and Yong, B., 2020. Quasi-Global Evaluation of IMERG and GSMaP Precipitation Products over Land Using Gauge Observations. Water, 12(1), 243. https://doi.org/10.3390/w12010243

10. Gavrikov, A.V., 2017. Estimating the Reproduction Quality of Precipitation over the North Atlantic and Influence of the Hydrostatic Approximation in the WRF-ARW Atmospheric Model. Oceanology, 57(2), pp. 232-238. https://doi.org/10.1134/S0001437017020047

11. Lockhoff, M., Zolina, O., Simmer, C. and Schulz, J., 2019. Representation of Precipitation Characteristics and Extremes in Regional Reanalyses and Satellite- and Gauge-Based Estimates over Western and Central Europe. Journal of Hydrometeorology, 20(6), pp. 11231145. https://doi.org/10.1175/JHM-D-18-0200.1

12. Koistinen, J. and Saltikoff, E., 1998. Experience of Customer Products of Accumulated Snow, Sleet and Rain. In: C. G. Collier, ed., 1998. COST 75 Advanced Weather Radar Systems: International Seminar, Locarno, Switzerland, 23-27 March 1998: Proceedings. Luxembourg: European Commission, pp. 397-406. Available at: https://op.europa.eu/fr/publication-detail//publication/404fb559-9d41-4002-a7e0-9a08c81fd264 [Accessed: 1 September 2021].

13. Huffman, G., Bolvin, D.T., Braithwaite, D., Hsu, K., Joyce, R., Kidd, C., Nelkin, E.J., Sorooshian, S., Tan, J. and Xie, P., 2020. Algorithm Theoretical Basis Document (ATBD) Version 06. NASA Global Precipitation Measurement (GPM) Integrated Multi-satellitE Retrievals for GPM (IMERG). [online] Available at: https://gpm.nasa.gov/sites/default/files/2020-05/IMERG_ATBD_V06.3.pdf [Accessed: 1 September 2021].

14. Tan, J., Huffman, G.J., Bolvin, D.T. and Nelkin, E.J., 2019. IMERG V06: Changes to the Morphing Algorithm. Journal of Atmospheric and Oceanic Technology, 36(12), pp. 24712482. https://doi.org/10.1175/JTECH-D-19-0114.1

15. Schneider, U., Becker, A., Finger, P., Meyer-Christoffer, A., Ziese, M. and Rudolf, B., 2014. GPCC's New Land Surface Precipitation Climatology Based on Quality-Controlled In Situ Data and Its Role in Quantifying the Global Water Cycle. Theoretical and Applied Climatology, 115(1-2), pp. 15-40. https://doi.org/10.1007/s00704-013-0860-x

16. Cornes, R.C., van der Schrier, G., van den Besselaar, E.J.M. and Jones, P.D., 2018. An Ensemble Version of the E-OBS Temperature and Precipitation Data Sets. Journal of Geophysical Research: Atmospheres, 123(17), pp. 9391-9409. https://doi.org/10.1029/2017JD028200

17. Kotlarski, S., Keuler, K., Christensen, O.B., Colette, A., Déqué, M., Gobiet, A., Goergen, K., Jacob, D. and Lüthi, D. [et al.], 2014. Regional Climate Modeling on European Scales: A Joint Standard Evaluation of the EURO-CORDEX RCM Ensemble. Geoscientific Model Development, 7(4), pp. 1297-1333. https://doi.org/10.5194/gmd-7-1297-2014

18. Aleshina, M.A., Semenov, V.A. and Chernokulsky, A.V., 2019. Study of the Role of Global and Regional Factors in Changing the Extremes of Summer Precipitation on the Black Sea Coast of the Caucasus with the Use of Results of Experiments with the Climate Model. Fundamental and Applied Climatology, 3, pp. 59-75. doi:10.21513/2410-8758-2019-3-59-75 (in Russian).

19. Raimonet, M., Oudin, L., Thieu, V., Silvestre, M., Vautard, R., Rabouille, C. and Le Moigne, P., 2017. Evaluation of Gridded Meteorological Datasets for Hydrological Modeling. Journal of Hydrometeorology, 18(11), pp. 3027-3041.doi:10.1175/JHM-D-17-0018.1

20. Laiti, L., Mallucci, S., Piccolroaz, S., Bellin, A., Zardi, D., Fiori, A., Nikulin, G. and Majone, B., 2018. Testing the hydrological coherence of High-Resolution Gridded Precipitation and Temperature Data Sets. Water Resources Research, 54(3), pp. 1999-2016. https://doi.org/10.1002/2017WR021633 
21. Camici, S., Ciabatta, L., Massari, C. and Brocca, L., 2018. How Reliable are Satellite Precipitation Estimates for Driving Hydrological Models: A Verification Study over the Mediterranean Area. Journal of Hydrology, 563, pp. 950-961. https://doi.org/10.1016/j.jhydrol.2018.06.067

22. Ved, I.P., 2000. [Climatological Atlas of Crimea]. Simferopol: Tavriya-Plus, 120 p. (in Russian).

23. Lipinskyi, V.M., Diachuk, V.A. and Babichenko, V.M., eds., 2003. [Climate of Ukraine]. Kyiv: Vydavnytstvo Raievskoho, 343 p. (in Ukrainian).

24. Efimov, V.V. and Komarovskaya, O.I., 2015. Breeze Circulation in the Crimean Region Atmosphere. Physical Oceanography, (6), pp. 69-78. https://doi.org/10.22449/1573-160X2015-6-69-78

25. Efimov, V.V., 2017. Numerical Simulation of Breeze Circulation over the Crimean Peninsula. Izvestiya, Atmospheric and Ocean Physics, 53(1), pp. 84-94. https://doi.org/10.1134/S0001433817010042

26. Prakash, S., Ramesh Kumar, M.R., Mathew, S. and Venkatesan, R., 2018. How Accurate are Satellite Estimates of Precipitation over the North Indian Ocean? Theoretical and Applied Climatology, 134(1-2), pp. 467-475. https://doi.org/10.1007/s00704-017-2287-2

27. Dunaieva, Ye.A. and Kovalenko, P.I., 2013. River Basins Typification of Crimea by Agrolandscapes and Ecological Load. Scientific Journal of Russian Scientific Research Institute of Land Improvement Problems, (4), pp. 157-167 (in Russian).

28. Tian, F., Hou, S., Yang, L., Hu, H. and Hou, A., 2018. How Does the Evaluation of the GPM IMERG Rainfall Product Depend on Gauge Density and Rainfall Intensity? Journal of Hydrometeorology, 19(2), pp. 339-349. https://doi.org/10.1175/JHM-D-17-0161.1

About the authors:

Anatolii E. Anisimov, Senior Research Scientist, Marine Hydrophysical Institute of RAS (2 Kapitanskaya St., Sevastopol, 299011, Russian Federation), Ph. D. (Phys.-Math.), ORCID ID: 00000002-5530-5608, ResearcherID: ABA-1705-2020, Scopus Author ID: 42561044300, anatolii.anisimov@mhi-ras.ru

Vladimir V. Efimov, Head of Atmosphere and Ocean Interaction Department, Marine Hydrophysical Institute of RAS (2 Kapitanskaya St., Sevastopol, 299011, Russian Federation), Dr. Sci. (Phys.-Math.), Professor, ORCID ID: 0000-0002-4262-9902, ResearcherID: P-2063-2017, Scopus Author ID: 7202138991, vefim38@mhi-ras.ru

Margarita V. Lvova, Senior Research Scientist, Department of Geophysical Monitoring and Research, FGBI "MGO" (7 Karbyshev St., St. Petersburg, 194021, Russian Federation), rita_lvova@mail.ru

Contribution the authors:

Anatolii E. Anisimov - conceptualization, methodology, data processing, visualization, original draft

Vladimir V. Efimov - methodology, discussion, manuscript review and editing

Margarita V. Lvova - discussion, data processing, manuscript review and editing

All the authors have read and approved the final manuscript.

The authors declare that they have no conflict of interest. 